\title{
Vibrant Soundbridge and Bone Conduction Hearing Aid in Patients with Bilateral Malformation of External Ear
}

\author{
Maria Fernanda Capoani Garcia Mondelli ${ }^{1}$ Thais Cristina Barbosa Mariano ${ }^{1}$ Heitor Marques Honório ${ }^{1}$ \\ Rubens Vuono de Brito ${ }^{2}$ \\ ${ }^{1}$ Department of Phonoaudiology, Faculdade de Odontologia de Bauru, \\ Universidade de São Paulo - USP, Bauru, SP, Brazil \\ ${ }^{2}$ Department of Otolaryngology, Universidade de São Paulo, São \\ Paulo, São Paulo, Brazil \\ Address for correspondence Maria Fernanda Capoani Garcia Mondelli, \\ PhD, Department of Phonoaudiology, Faculdade de Odontologia de \\ Bauru - USP, Al. Octavio Pinheiro Brisola 9-75, Bauru, São Paulo \\ 17012901, Brazil (e-mail: mfernandamondelli@hotmail.com).
}

Int Arch Otorhinolaryngol 2016;20:34-38.

\begin{abstract}
Introduction Hearing loss is the most common clinical finding in patients with malformation of the external ear canal. Among the possibilities of treatment, there is the adaptation of hearing aids by bone conduction and the adaptation of implantable hearing aids.

Objective To assess speech perception with the use of Vibrant Soundbridge (VBS MED-EL, Innsbruck, Austria) associated with additional amplification in patients with bilateral craniofacial malformation.

Method We evaluated 11 patients with bilateral malformation over 12 years with mixed hearing loss or bilateral conductive. They were using the Softband (Oticon Medical, Sweden) and bone conduction hearing aid in the ear opposite the one with the VSB. We performed the evaluation of speech perception using the Hearing in Noise Test. Results Participants were eight men and three women with a mean of 19.5 years. The

\section{Keywords}

- abnormalities

- hearing aid

- speech perception signal / noise ratio presented significant results in patients fitted with VSB and bone conduction hearing aid.

Conclusion The results of speech perception were significantly better with use of VBS combined with bone conduction hearing aids.
\end{abstract}

\section{Introduction}

The malformation of the external ear canal, a type of atresia, occurs in about one in every 20,000 live births. ${ }^{1}$ It is characterized by the absence or deformity of the pavilion, aplasia, or hypoplasia of the external auditory canal, middle ear deformities, and, occasionally, internal ear deformities. ${ }^{1}$

Hearing loss is the most common clinical finding, with type and extent of loss relating to the location of the malformation: external ear, middle ear, and / or inner ear. ${ }^{2}$

The treatment possibilities for this malformation include the adaptation of hearing aids by bone conduction, the adaptation of the implantable hearing aid, or surgical reconstruction of the ear. ${ }^{2}$

The use of an individual hearing aid (HA) is not possible in cases of agenesis or external auditory canal stenosis because of the impossibility of stimulation by air. ${ }^{3}$ In such cases, a bone conduction hearing aid may be an option.

Complaints of headaches from bow pressure and dissatisfaction with the aesthetic visibility of bone conduction hearing aid components are common among teens and tweens. All these factors combined lead to reduced use of the device. ${ }^{4}$

The Vibrant Soundbridge (VBS - MED-EL, Innsbruck, Austria) is a surgically implantable middle ear HA consisting of two components: the implantable internal component and received

June 26, 2015

accepted

July 14, 2015

published online

October 28, 2015
DOI http://dx.doi.org/

10.1055/s-0035-1566155. ISSN 1809-9777.
Copyright $\odot 2016$ by Thieme Publicações License terms Ltda, Rio de Janeiro, Brazil

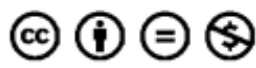


an external drive. The outside is fixed to the skin, on the patient's head, with a magnet. The device works with batteries, similar to other hearing aids, and it contains a microphone that picks up sound and transmits it through the skin to the internal receiver. $^{5}$

The advantages of binaural hearing are widely publicized and documented. The ability to use both ears functionally promotes a better understanding of speech in a noisy or reverberant environment. The ability to locate sounds is highly dependent on the ability to perceive sounds simultaneously in both ears. ${ }^{6}$ In addition, binaural hearing plays a fundamental role in monitoring and control of numerous alerts and guidance situations in peoplés daily routine. An interference or impairment of this skill often brings feelings of insecurity in relation to the surrounding environment. ${ }^{7}$

Before the satisfactory results in patients with external ear malformation implanted with VSB system, became interested in studying the use of this device associated with the hearing aid, as an alternative to hearing rehabilitation.

The objective of the research was to evaluate speech perception with the use of VBS associated with another amplification device in patients presenting bilateral craniofacial malformation.

\section{Method}

This is a prospective cohort study, conducted upon approval of the Research Ethics Committee (345/2011).

The population consisted of individuals fitted with surgically implantable middle ear HA (VBS) during 2013.

We selected individuals based on the following inclusion criteria: older than 12 years of age; presenting bilateral malformations of the external ear with or without middle ear malformation; bilateral conductive or mixed hearing loss; and having communication difficulties without the HA.

The exclusion criteria were: individuals with central or retrocochlear auditory disorders; individuals with otologic disorders, such as vertigo and Meniere's disease, tinnitus, hearing fluctuation, or inner ear malformations.

\section{Selection of Hearing Aids}

The patients used Softband Ponto (Oticon) by bone conduction and the Naída I SP (Phonak) hearing aid, set in the opposite ear to the VSB.

We used the nonlinear prescriptive method NAL-NL1 to calculate and set electroacoustic characteristics based on the tone thresholds entered previously.

The adjustments and prescriptive methods used were similar for VBS, Softband, and bone conduction HAs. Algorithms were triggered only by managing feedback, by holding an omnidirectional microphone.

After programming the HA, we performed the verification procedure with thresholds of measures in the free field with and without amplification. The minimum intensity was $30 \mathrm{~dB}$ SPL as the minimum value allowed, in accordance with the calibration of equipment.

The participants performed the speech perception test three months after activation of the VSB.

\section{Speech Perception Test}

The speech perception test was conducted in two distinct situations through HINT (Hearing In Noise Test), adapted to Brazilian Portuguese ${ }^{8}$ :

1. Speak in quiet (Silence): the signal away from the front of the individual in a noise-free test condition ( $0^{\circ}$ azimuth).

2. Speak with frontal noise (Noise Front): the signal and noise are placed directly in front of the individual in a sound condition at $0^{\circ}$ azimuth.

For each condition, we displayed a list of 20 sentences, randomly selected by the HINT PRO software itself. Participants received as guidelines the oral instructions contained in the HINT manual.

The evaluator considered the sentence correct when the participant properly repeated all essential words. In this case, the evaluator pressed the "yes" button on the software screen. If the evaluator selected "yes" after the first performance, the program presented the second sentence at an intensity $4 \mathrm{~dB}$ below that of the first sentence.

To evaluate the silence, we initially set the level of speech at $45 \mathrm{dBA}$. This level varied according to participants' answers. If the participant did not correctly repeat the sentence, the intensity level progressively increased by $4 \mathrm{~dB}$ steps until the participant could correctly repeat the sentence.

The score for the silence test is expressed in dBA and represents the recognition threshold for $50 \%$ of the sentences.

As for the evaluation in noise, we kept this level fixed at $65 \mathrm{dBA}$. The level of presentation of the sentences varied in the same manner described for the mute condition. The score in $\mathrm{dB}$ is the signal-to-noise threshold after going through a list of 20 sentences. Thus, the lower the signalto-noise ratio, the better the participants speech perception in this condition.

The HINT was performed in four different situations:

1. Without Vibrant Soundbridge and with Softband: the Softband functions as a conventional bone conductor, adjustable by means of an elastic band, adapting to any head size.

2. With Vibrant Soundbridge and Softband.

3. Without Vibrant Soundbridge, with bone conduction HA: the HA functions as a headband with a bone vibrator.

4. With Vibrant Soundbridge and bone conduction hearing aid.

\section{Statistical Analysis}

We analyzed the results of the speech perception evaluation in silence using the nonparametric Friedman.

We analyzed the evaluation of individuals in the noise situation with the ANOVA test.

We considered the significance level of $p<0.001$ for the statistical procedure results in silence and $p<0.050$ for the results in noise.

\section{Results}

The study group involved 11 individuals of both sexes ( 8 men and 3 women) with a mean of 19.5 years, with bilateral malformation of ears and severe mixed bilateral hearing loss. 


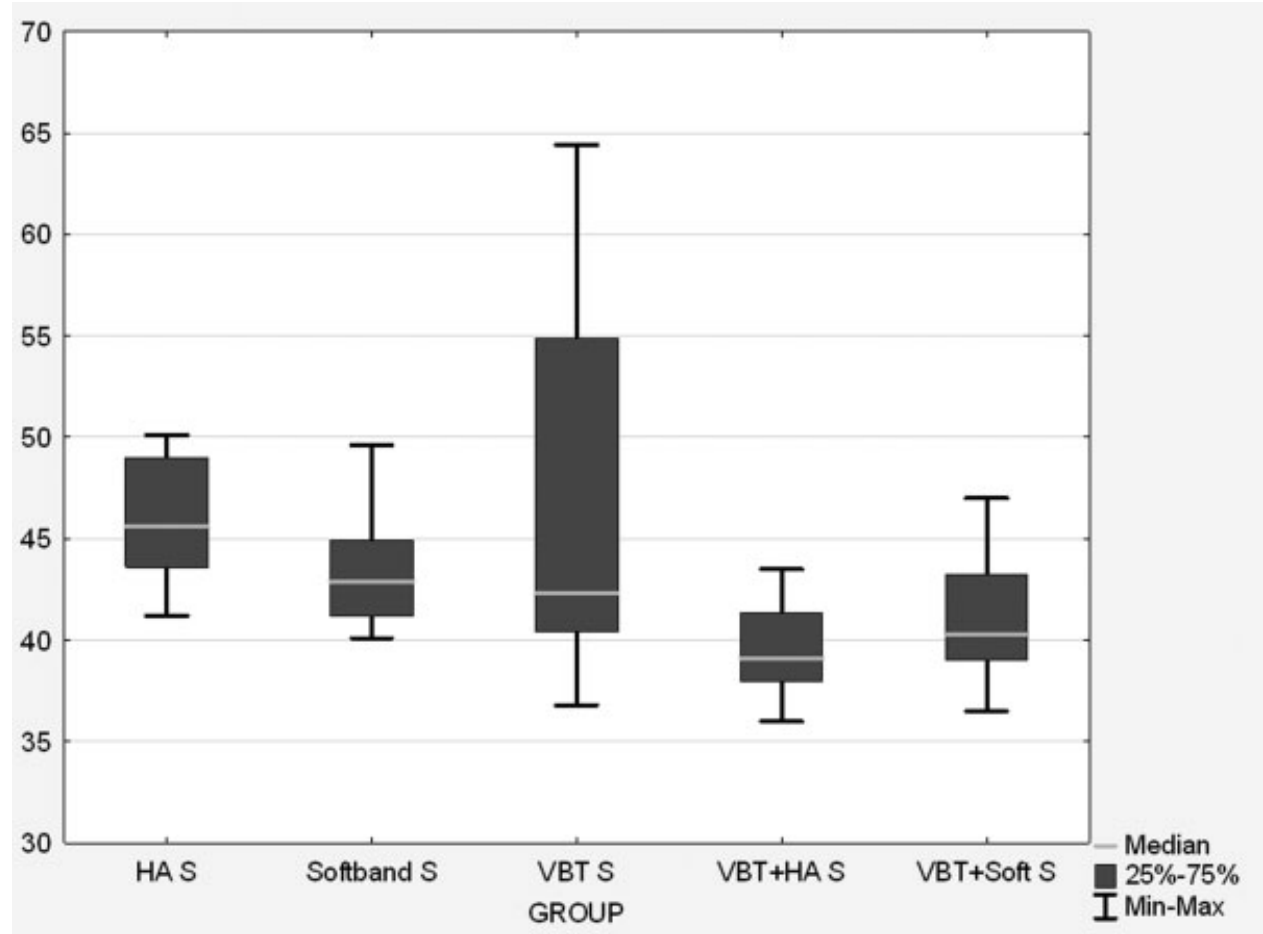

Fig. 1 Speech perception responses of individuals in silence situation. Abbreviations: HA hearing aid; VBT, Vibrant Sound Bridge.

The HINT results in the quiet situation are in - Fig. 1.

The responses obtained in the noise situation are in - Fig. 2.

\section{Discussion}

The adaptation of bilateral amplification devices presupposes the possibility of interaction between the two auditory path- ways and, thus, provides the individual with binaural hearing loss with a sound of superior quality in terms of clarity, redundancy, binaural summation effect, stereo, and free from head shadow effect. ${ }^{6}$ Thus, it seems consistent to suggest that the adaptation of bilateral amplification devices should be privileged whenever there is a contraindication to such.,

Researchers investigated the simultaneous use of VBS and digital HA in eight adults in the following situations: without

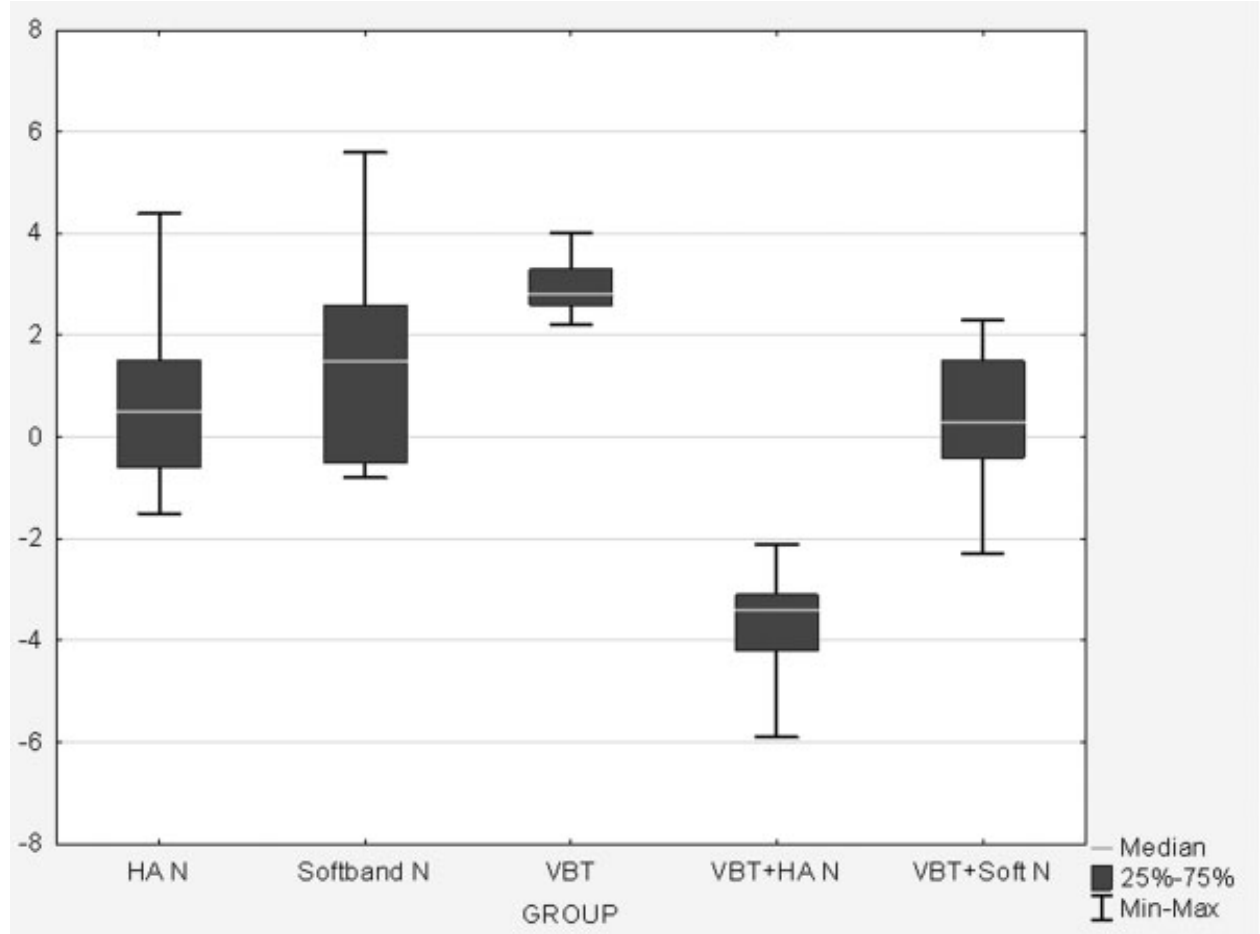

Fig. 2 Speech perception responses of individuals in noise situation. Abbreviations: HA hearing aid; VBT, Vibrant Sound Bridge. 
amplification, unilateral adaptation of VBS, VBS associated with HA with omnidirectional microphone, and HA with omnidirectional microphone unilaterally. The study concluded that the adjustment associated with the amplification devices benefited users in speech perception in silence, with no significant results in the evaluation in the noise condition. $^{10}$

The results from this study show that there was no significant difference between the responses obtained in the silence with individual use of VBS $x$ HA and VBS $x$ Softband. Similar data were found by researchers that evaluated the speech perception of 19 adults who used conventional HA for a period of three months and could not adapt due to chronic irritation, aesthetic, occlusion effect, and insufficient amplification. Participants were surgically fitted with VBS and, after comparing the evaluation of speech perception, stated that there was no difference between the results obtained with $\mathrm{HA}$ and VBS. ${ }^{11}$

Another study performed a comparison of speech perception with the use of VBS and open fitting HA with seven adults diagnosed with sensorineural hearing loss at high frequencies. The research found that the VBS gave greater amplification to higher frequencies compared with open fit, however there was no significant difference in relation to speech perception. $^{12}$

In normal hearing individuals, the hearing threshold improved $\sim 3 \mathrm{~dB}$, if we go from monaural stimulation to binaural stimulation. This situation is often called binaural redundancy, and may render improved results in terms of speech perception. ${ }^{13}$ When an individual tries to understand a vocal stimulus with only one ear, there is a decrease in signal playability. Individuals with bilateral hearing impairment, when bilaterally fit, have better discrimination capacity in noise than in monaural fitting. ${ }^{14-16}$

Some authors ${ }^{17-19}$ emphasize that unilateral hearing is insufficient in several aspects related to learning, sound localization, and speech recognition in noise situation. The use of contralateral HA to VBS favored the speech perception in silence and noisy situations. Binaurality can offer benefits in improving the perception of words, greater access to sounds, improved oralization, and sound localization. ${ }^{18-20}$

The results obtained with use of bilateral amplification indicated significant improvement in speech perception in silence and noise situation. In a case study with a six-year-old boy, the VBS was adapted with an interval of two months between surgeries; bilateral adaptation resulted in a $100 \%$ score in the speech perception assessment in quiet and in noise. $^{21}$

Experiments indicate that the VBS provides significant results in free field thresholds to search for individuals with bilateral ear malformation with $55.1 \mathrm{~dB}$ gain for all frequencies studied. ${ }^{22}$ Patients with bilateral atresia had a score of $97 \%$ correct for two-syllable words in 65dBSPL after binaural adaptation. ${ }^{23}$

It is possible to confirm that bilateral adaptation favors perception of speech, regardless of which amplification device used. Probably, the bilateral implementation of the VBS would be the ideal for the cases evaluated in this study, although this decision should fall under the ENT physiciańs responsibility. A team of researchers evaluated quantitatively and qualitatively a group of 15 patients with sensorineural hearing loss, with sequential implant VBS and revealed an improvement in speech perception in silence and noise situation. ${ }^{24}$

Our research shows that the use of HA associated with the VBS provided a significant improvement in speech perception in silence and noise situation (Graphs 1 and 2). However, there is difficulty in the effective use of the bow due to the headaches caused by pressure arc on the mastoid and the negative psychosocial aesthetic impact of visible components of the hearing aid. ${ }^{25}$ Thus, bilateral indication for surgery is a viable option for the study population.

Bilateral VSB is a clinical reality, but not all users will have access to this treatment option for audiological, medical and family reasons.

\section{Conclusion}

The results of speech perception were significantly better with use of VBS associated with bone conduction HA.

\section{References}

1 Mendonça OLC, Costa SS. Otologia clínica e cirúrgica. Rio de Janeiro: Revinter; 2000

2 Castiquini EAT, Silveira TS, Shayeb DR, Meyer ASA. Avaliação Audiológica de Indivíduos Portadores de Malformação de Orelha. Int Acrh Otorhinolaryngol 2006;10:98-103

3 Wazen JJ, Caruso M, Tjellstrom A. Long-term results with the titanium bone-anchored hearing aid: the U.S. experience. Am J Otol 1998;19(6):737-741

4 Habal M, Frans N, Zelski R, Scheuerle J. Percutaneous boneanchored hearing aid. J Craniofac Surg 2003;14(5):637-642

5 Lenarz T, Weber BP, Issing PR, et al. The Vibrant Soundbridge $\AA$ : a new kind of hearing aid for sensorineural hearing loss, part 2: audiological results. Laryngorhinootologie 2001; $80: 370-380$

6 Dillon H. Binaural and bilateral considerations in hearing aids and fitting. In: Dillon H, editor. Hearing Aids. Turramurra: Boomerang Press; 2001:370-403

7 Wieselberg MB, Iorio MCM. Adaptação de prótese auditiva e a privação da audição unilateral: avaliação comportamental e eletrofisiológica. Braz J Otorhinolaryngol 2012;78:69-76

8 Bevilacqua MC, Banhara MR, Da Costa EA, Vignoly AB, Alvarenga KF. The Brazilian Portuguese hearing in noise test. Int J Audiol 2008;47(6):364-365

9 Holmes AE. Bilateral amplification for the elderly: are two aids better than one? Int J Audiol 2003;42(Suppl 2):S63-S67

10 Saliba I, Calmels MN, Wanna G, et al. Binaurality in middle ear implant recipients using contralateral digital hearing AIDS. Otol Neurotol 2005;26(4):680-685

11 Gunduz B, Atas A, Bayazıt YA, Goksu N, Gokdogan C, Tutar H. Functional outcomes of Vibrant Soundbridge applied on the middle ear windows in comparison with conventional hearing aids. Acta Otolaryngol 2012;132(12):1306-1310

12 Sziklai I, Szilvássy J. Functional gain and speech understanding obtained by Vibrant Soundbridge or by open-fit hearing aid. Acta Otolaryngol 2011;131(4):428-433

13 Brookhurst AW, Plomp R. The effect of head-induced time and level differences on speech intelligibility in noise. J Acoust Soc Am 1988;83:1508-1516 
14 Ross M. Binaural versus monoaural hearing aid amplification for hearing impaired individuals. In: Libby ER(Ed.), Bin Hea. Arnolif li. Chicago: Zenetron; 1980:1-21

15 Byrne D. Binaural hearing aid fitting: research findings and clinical applications. In:Lybby ER (Ed.), Bin Hear Amplif II. Chicago: Zenetron; 1980:23-73

16 Byrne D. Clinical issues and options in binaural hearing aid fitting. Ear Hear 1981;2(5):187-193

17 Bess FH, Tharpe AM, Gibler AM. Auditory performance of children with unilateral sensorineural hearing loss. Ear Hear 1986;7(1):20-26

18 Feuerstein JF. Monaural versus binaural hearing: ease of listening, word recognition, and attentional effort. Ear Hear 1992;13(2):80-86

19 Offeciers E, Morera C, Müller J, Huarte A, Shallop J, Cavallé L. International consensus on bilateral cochlear implants and bimodal stimulation. Acta Otolaryngol 2005;125(9):918-919

20 Ching TYC, Psarros C, Hill M, Dillon H, Incerti P. Should children who use cochlear implants wear hearing aids in the opposite ear? Ear Hear 2001;22(5):365-380
21 Frenzel H, Hanke F, Beltrame M, Wollenberg B. Application of the Vibrant Soundbridge in bilateral congenital atresia in toddlers. Acta Otolaryngol 2010;130(8):966-970

22 Zernotti ME, Arauz SL, Di Gregorio MF, Arauz SA, Tabernero P, Romero MC. Vibrant Soundbridge in congenital osseous atresia: multicenter study of 12 patients with osseous atresia. Acta Otolaryngol 2013;133(6):569-573

23 Lesinskas E, Stankeviciute V, Petrulionis M. Application of the Vibrant Soundbridge middle-ear implant for aural atresia in patients with Treacher Collins syndrome. J Laryngol Otol 2012; 126(12):1216-1223

24 Garin P, Schmerber S, Magnan J, et al. Bilateral vibrant soundbridge implantation: audiologic and subjective benefits in quiet and noisy environments. Acta Otolaryngol 2010;130(12): 1370-1378

25 Paccola EC, Fernandes JC, Mondelli MF. Amplification by bone conduction in congenital malformations: patient benefits and satisfaction. Braz J Otorhinolaryngol 2013;79(3):359-365 